\title{
Dez escolas, dois padrões de qualidade. Uma pesquisa em dez escolas públicas de Ensino Médio do Estado do Ceará
}

\author{
André Haguette ${ }^{a}$ \\ Márcio Kleber Morais Pessoa ${ }^{b}$ \\ Eloísa Maia Vidal ${ }^{c}$
}

\section{Resumo}

Tomando por base os resultados no Enem de 2011, realizou-se, ao longo de 2013 e 2014, uma pesquisa comparativa de cinco das dez escolas de Ensino Médio da rede estadual do Estado do Ceará com melhor desempenho, e de cinco entre as dez com rendimento mais fraco, quatro do interior e seis da capital. Os instrumentos de coleta de dados foram: visitas às escolas, entrevistas com um membro do núcleo gestor, com professores, alunos e funcionários e aplicação de um questionário numa turma de alunos e com professores. O objetivo era descobrir o que as escolas de melhor desempenho tinham que as de desempenho nitidamente insuficiente não tinham. A partir dos resultados, foi construído um "retrato falado" de cada escola, apontando suas principais características. Logo ficou evidenciado que existem dois padrões escolares mutuamente excludentes e irreconciliáveis, o que foi traduzido em duas tipologias ideal-típicas reveladoras da situação e susceptíveis de fornecer elementos para a elaboração de políticas educacionais. Este artigo omite os "retratos falados" de cada escola por falta de espaço, e concentra-se na apresentação e discussão das duas tipologias de maneira a explicitar e explicar o duplo padrão, verdadeiro dualismo, existente entre estabelecimentos de uma mesma rede escolar pública. A conclusão levanta questionamentos provocados pela pesquisa.

Palavras-chave: Ensino Médio público. Motivação dos alunos. Clima escolar. Políticas educacionais. Desigualdade escolar.

\footnotetext{
a Universidade Federal do Ceará - UFC, Departamento de Ciências Sociais. Fortaleza, Ceará, Brasil.

b Rede Estadual de Educação Básica do Estado do Ceará. Fortaleza, Ceará, Brasil.

c Universidade Estadual do Ceará - UECE. Fortaleza, Ceará, Brasil.
} 


\section{Introdução}

A ideia desta pesquisa surgiu a partir da leitura de uma reportagem do jornal fortalezense $O$ Povo, publicada em 26 de fevereiro de 2013, listando as dez escolas públicas da rede estadual de Ensino Médio do Estado do Ceará com melhor desempenho no exame do Enem de 2011. Essa lista foi elaborada pelo Instituto de Pesquisa e Estratégia Econômica do Estado do Ceará (Ipece) e divulgada no dia anterior ao da publicação da matéria. A reportagem despertou o interesse de conhecer as razões que levaram essas escolas a se destacar em comparação com outras escolas públicas geridas pela mesma Secretaria de Educação.

A partir da ideia sugerida pela reportagem, ponderou-se que uma pesquisa específica com dez escolas que apresentaram melhores resultados poderia não permitir identificar aspectos relacionados ao ambiente escolar que captassem elementos capazes de explicar tais resultados. Assim, optou-se por comparar cinco, entre as dez escolas mais bem-sucedidas, com cinco escolas, entre as dez com o menor desempenho no mesmo exame. Essa comparação, dos dois grupos de escola situados em extremos da escala de desempenho, poderia ser significativa e explicativa dos rendimentos diferenciados dos alunos.

No Estado do Ceará, desde a criação do novo Enem, em 2009, e a adoção deste exame para acesso a vagas em instituições públicas federais de Ensino Superior, a Secretaria de Educação do Estado (Seduc) vem empreendendo esforços no sentido de estimular os alunos do $3^{\circ}$ ano do Ensino Médio das escolas públicas a se inscreverem e realizarem as provas. Ações nessa direção acontecem durante todo o ano letivo, em todos os anos, desde 2010, e algumas escolas chegam a inscreverem $100 \%$ dos seus alunos matriculados no $3^{\circ}$ ano do Ensino Médio. Assim, embora os autores reconheçam que o Enem é um exame por adesão, no caso do Ceará, a política adotada pela Seduc redimensiona-o, colocando em segundo plano seu caráter voluntário e criando um ethos na escola, em que todos se sentem impelidos a participar.

Apresenta-se, aqui, portanto, os resultados de um estudo comparativo de cinco entre as dez escolas que obtiveram os melhores resultados de desempenho no Enem 2011, com cinco entre as dez escolas de menor desempenho no mesmo exame. A pesquisa de campo nas escolas foi realizada durante o ano de 2013 e início de 2014, e a elaboração do relatório final foi concluída em dezembro de 2014, sendo enviado no mesmo mês à revista Ensaio. A pesquisa se caracteriza como de natureza qualitativa e etnográfica, contando com apoio de questionários semiestruturados que orientaram as entrevistas realizadas com os gestores, professores e alunos; utilizou-se, também, o diário de campo para registro por 
parte dos pesquisadores de eventos, destaques e impressões acerca de cada uma das escolas pesquisadas. Os resultados obtidos adquirem uma dimensão significativa na medida em que se colocam como autoexplicativos da clivagem entre os dois conjuntos de escolas de uma mesma rede escolar.

Escolher o Enem para caracterizar os resultados de uma escola traz questionamentos sobre o que vem a significar o conceito de "qualidade escolar". Certamente, sucessos na aprendizagem de conteúdos cognitivos não são tudo o que se espera de uma escola de qualidade. Instrução não significa educação, escola de qualidade. O conceito de qualidade, portanto, incorpora, além de sólidos conhecimentos, uma formação ética, política e emocional, preparando para o mercado de trabalho, mas também para a cidadania, o convívio social e a felicidade pessoal do aluno, conforme preconiza as Diretrizes Curriculares Nacionais para o Ensino Médio (BRASIL, 2012), ao afirmar:

Art. $4^{\circ}$ - As unidades escolares que ministram esta etapa da Educação Básica devem estruturar seus projetos político-pedagógicos considerando as finalidades previstas na Lei $\mathrm{n}^{\circ}$ 9.394/96 (Lei de Diretrizes e Bases da Educação Nacional):

II - a preparação básica para o trabalho e a cidadania do educando para continuar aprendendo, de modo a ser capaz de se adaptar a novas condições de ocupação ou aperfeiçoamento posteriores;

III - o aprimoramento do educando como pessoa humana, incluindo a formação ética e o desenvolvimento da autonomia intelectual e do pensamento crítico;

IV - a compreensão dos fundamentos científico-tecnológicos dos processos produtivos, relacionando a teoria com a prática.

Esta pesquisa, portanto, trabalha com um conceito estreito e limitado de qualidade escolar, a saber: a aprendizagem de conhecimentos suficiente para se ter um bom desempenho no ENEM. É pouco, mas é o critério utilizado para certificar o Ensino Médio, a entrada no Ensino Superior e na avaliação e comparação das escolas de Ensino Médio entre si. A pesquisa somente registra, empiricamente, as diferenças entre cada grupo de escolas, destacando atitudes e comportamentos distintos relatados pelos diversos componentes de cada escola. É significativo observar que as cinco escolas com melhor desempenho de seus alunos no ENEM possuem um conjunto de variáveis similares, enquanto as cinco escolas de fraco 
desempenho compartilham, também, um conjunto de variáveis, mas opostas às do grupo anterior, o que leva a concluir que a pesquisa tenha encontrado uma explicação coerente e provável, embora, talvez, não a única possível.

\section{As escolas e seus contextos}

A relação das dez escolas de melhores resultados compreendia escolas de perfil e localização diferentes. Duas eram escolas militares, sete faziam parte de um projeto de escolas profissionalizantes e uma funcionava em tempo integral, embora não fosse profissionalizante. Seis localizavam-se na capital Fortaleza e quatro, no interior. Foram selecionadas uma escola militar, a escola de tempo integral, que não estava vinculada ao projeto de escolas profissionalizantes, uma profissionalizante, que funcionava em uma antiga escola renovada - as três localizadas em Fortaleza - e duas escolas profissionalizantes no interior. Desta forma, ter-se-ia a necessária diversidade. Quanto às escolas de fraco desempenho no Enem, três na capital e duas no interior, foram escolhidas sem muito saber o que se esperar. Uma dessas escolas revelou-se uma das cinco "escolas do campo" mantidas pela Secretaria de Educação do Estado, em parceria com sindicatos rurais e objetos de uma programação especial para atendimento a populações agrícolas assentadas e, consequentemente, diferentes da clientela das escolas comuns, interioranas ou urbanas.

A pesquisa consistiu em visitar essas escolas utilizando-se das seguintes técnicas: diário de campo, entrevistas abertas com o núcleo gestor, professores dentro da sala dos professores, funcionários e uma turma de alunos, em sua maioria, do $3^{\circ}$ ano, além da aplicação de questionários semiestruturados específicos aos professores e alunos com quem fizemos a entrevista. No entanto, o método que trouxe mais frutos a esta pesquisa foi o método comparativo, indispensável a análises sociais, como ensinaram e praticaram Max Weber (2000), e Émile Durkheim (1971). Comparar entre si os dois grupos de escolas traz uma compreensão que dificilmente seria alcançada adotando outro procedimento.

Vale enfatizar que a pesquisa ora apresentada não recebeu nenhum financiamento e foi realizada por puro interesse acadêmico e social dos autores, que, portanto, arcam com todas as responsabilidades e imperfeições do empreendimento. Notáveis, todavia, foram a receptividade das pessoas empenhadas nos afazeres de cada escola e sua decisão de colaborar com a pesquisa. Os pesquisadores agradecem e honrarão sua promessa de voltar às escolas para apresentar e discutir os resultados.

Este estudo, portanto, teve um só foco: o que as escolas públicas com elevado desempenho no exame do Enem têm e o que falta às escolas de desempenho 
precário, como dito anteriormente. Os pesquisadores tentaram encontrar respostas para isso a partir da visão dos sujeitos escolares sobre seus estabelecimentos educacionais, em acordo com os métodos supracitados. Isso significa que muitos outros temas relevantes não foram sequer mencionados e ainda menos pesquisados. Não se investigou a metodologia adotada em salas de aula; não se analisou o currículo nem o seu cumprimento; o desenvolvimento das aulas não foi observado; não se aprofundou as taxas de rendimentos nem seus motivos. É evidente que pesquisas específicas e locais nesses pontos e outros poderiam ajudar as escolas a terem resultados bem mais expressivos, isso porque estudos recentes mostram o quanto professores pedagogicamente competentes, dedicados e habilidosos podem fazer diferenças na aprendizagem dos alunos (MCKINSEY \& COMPANY, 2007). A mesma coisa ocorre com ações de diretores bem formados. A gestão escolar é uma importante variável para a eficácia dos estabelecimentos escolares, conforme apontado por Braslavsky (2005) e por Barber e Mourshed (2007 apud WEINSTEIN; MUÑOZ, 2012). Mas o foco era outro: identificar os componentes que estabelecem diferenças fundamentais entre os dois grupos de escola. E para a surpresa dos pesquisadores, chegou-se rapidamente a um ponto de saturação; tanto as entrevistas, como as respostas aos questionários e as observações iam se repetindo e reforçando-se umas às outras.

Como consequência do método comparativo, os pesquisadores construíram duas tipologias dessas escolas: uma das escolas com bom desempenho e outra das escolas com resultados mais fracos. A análise dessas duas tipologias permitiu constatar que havia dois padrões de estabelecimentos escolares, com características próprias, indisfarçáveis e intransferíveis, levando a uma conclusão claríssima e instigante: não há homogeneidade no sistema público de Ensino Médio do Estado do Ceará. A heterogeneidade é marcante e cruel, explicando perfeitamente os resultados divergentes no exame do Enem. Este artigo apresenta e discute essas tipologias, abrindo a possibilidade de elaborar, pragmaticamente, um feixe de políticas públicas para melhorar a qualidade dos dois grupos de escola.

Contudo, antes de iniciar a descrição comentada das tipologias, convém dizer algumas palavras sobre o perfil socioeconômico dos alunos das dez escolas, já que, por sua vez, os professores possuem o perfil e as qualificações comuns a todos os docentes da rede escolar estadual, não havendo, portanto, diferenças relevantes entre os docentes dos dois grupos de escolas. Enquanto os alunos da escolar militar, aberta para filhos e familiares de militares e do público em geral, são filhos de pais com renda acima de dois salários mínimos, que não estão inscritos no Programa Bolsa Família e têm boa escolaridade, os alunos das outras nove escolas não se diferenciam socioeconomicamente falando, sendo filhos de famílias com renda abaixo de dois salários mínimos e inscritas no Bolsa Família em 80\% dos casos. 
Esses alunos cursaram o Ensino Fundamental público. Embora a lei da criação das escolas profissionalizantes permita que $20 \%$ dos alunos tenham estudado em escolas privadas no Ensino Fundamental, a presença nessas escolas de alunos com esse perfil ainda é tímida.

De qualquer forma, o que se deseja ressaltar aqui é que os dados da pesquisa revelam não haver diferença socioeconômica entre os alunos dos dois grupos, prevalecendo famílias de baixa renda, tendo, entre outras consequências, aquela que os pais são portadores de uma escolaridade precária. A renda familiar, portanto, não é, aqui, fator explicativo do maior ou menor sucesso cognitivo dos alunos das nove escolas. Vale insistir: a renda familiar não pode ser tomada como variável explicativa neste caso, pois as famílias dos alunos dessas nove escolas estão rigorosamente na mesma faixa de renda. Da mesma forma, a pesquisa apurou que os alunos das dez escolas vivem, na sua grande maioria (em torno de $80 \%$ ), com pais e mães, e exceções são os que trabalham; a quase totalidade apenas estuda. Importa, no entanto, dizer que como a pesquisa tomou como objeto escolas e turmas funcionando pela manhã e/ou à tarde, ela nada adianta sobre o ensino noturno que, como é reconhecido, é crítico e possui características peculiares.

\section{Caracterização das escolas de melhor desempenho pedagógico}

\subsection{Desejo de aprender}

Talvez a caracterização de maior relevância das cinco escolas acima apresentadas, prontamente apanhada pela observação dos pesquisadores e anotada no diário de campo, seja a vontade e disposição prática dos alunos em aprender. Eles desejam aprender e têm satisfação em frequentar uma escola de dois turnos que os incita e leva a aprender. Os alunos manifestam orgulho de querer aprender e de se preparar para uma profissão que, em tese, lhes permitirão galgar mobilidade social. Há uma aspiração e uma convicção internalizadas de que o estudo é o caminho para vencer na vida e ter uma vida melhor do que a de seus pais. Eles não têm como "grupo de referência" (MERTON, 1968) seus pais; pelo contrário, apoiado por eles, os filhos almejam níveis profissionais e de vida superiores. Essa atitude dos alunos faz com que, na escola, se respire um "clima de estudo" e de alegria por ter a oportunidade de realmente aprender.

Essa característica é perceptível de diversas maneiras. Nas entrevistas coletivas e nos questionários individuais, raros são os alunos que dizem querer trabalhar imediatamente após o término do Ensino Médio; mesmo aqueles que assim se pronunciam, deixam claro que pretendem continuar os estudos de qualquer maneira. 
A grande maioria tem como objetivo internalizado, consciente e verbalizado entrar no Ensino Superior, formar-se e seguir uma carreira profissional. Outros dizem que vão continuar se especializando na profissão que estão aprendendo na escola - no caso das escolas profissionalizantes. Todos declaram ter uma atitude positiva em face do estudo, o que é confirmado pelos professores e pelo núcleo gestor. Em nenhuma dessas escolas os mestres encontram dificuldade para dar aulas, propor dever de casa e tarefas escolares. Isso é especialmente característico nas escolas que não são militares. Os alunos da escola militar se dedicam aos estudos sob a influência e a autoridade não somente do corpo docente, mas, sobretudo, dos pais. Impressionou os pesquisadores a leveza com que os alunos das quatro outras escolas aceitam nove horas de aula por dia e ainda o cumprimento de tarefas em casa, à noite (vale aqui relembrar que a escola militar não é de tempo integral).

Em tal ambiente escolar, e com o comprometimento dos alunos pelos estudos, não é surpreendente que os resultados acadêmicos apareçam e se fortaleçam pelos sucessos obtidos em uma espécie de efeito "bola de neve".

Os pesquisadores ficaram muito surpresos e impressionados pela descoberta de alunos de escolas públicas se dedicarem com tanta espontaneidade e consistência aos estudos. Claramente, não é essa doce música que se costuma ouvir quando se fala da escola pública. Mas, talvez, se deva dar a seguinte explicação: os alunos dessas escolas, tanto no interior como na capital, são recrutados a partir de um processo seletivo que elimina alunos menos preparados e que possuem dificuldades com os estudos. Provavelmente, são filhos de pais que, apesar de sua baixa renda e pouca escolaridade, acreditam que estudar é o caminho da mobilidade social. É bom frisar, todavia, que, anteriormente à seleção por essas escolas, houve uma primeira escolha feita pelas escolas privadas que recebem os alunos com notas mais elevadas e de famílias mais abastadas, o que não significa, necessariamente, os melhores alunos, se levar-se em consideração as qualidades humanas dos jovens. Um aluno pobre pode ter maior motivação, maior dedicação e maior perseverança.

Uma avaliação escolar internacional de grande renome - o Programa de Avaliação de Estudantes Internacionais (OECD, 2014) - mostra, com toda evidência, que alunos socioeconomicamente privilegiados, cujos pais têm uma escolaridade elevada, possuem uma boa aprendizagem escolar, e que alunos socioeconomicamente carentes têm um baixo nível de participação e engajamento na escola, um baixo nível de motivação e dedicação aos estudos e uma baixa autoestima com, portanto, uma aprendizagem deficiente. Entretanto, essas características não possuem uma força absolutamente determinante. Alguns alunos, $6 \%$, apresentam um alto grau 
de resiliência e conseguem quebrar esses condicionantes e igualar-se a alunos com alto grau de sucesso. Isso significa que, além de fatores externos ao aluno, tais como: escolaridade dos pais, situação de classe, ambiente social, há fatores internos, próprios à criança e ao adolescente, que os levam a desenvolver uma intensa vontade de aprender. Talvez, se trate desses $6 \%$ de resilientes.

\subsection{Autodisciplina coletiva}

Outra característica chocante e incontornável é que reina nessas escolas uma disciplina capaz de surpreender e impressionar as pessoas que se dispuserem a visitá-las. O "clima de estudo" é acompanhado por um "clima de disciplina", já que se trata de uma disciplina interiorizada que ocorre sem guardiões, nem vigilância, com exceção da escola militar, que coloca guardas a posto encarregados de vigiar os alunos e conduzi-los gentilmente a suas respectivas salas de aula após os intervalos. Nas outras, não há encarregados da disciplina e tudo corre na mais alta tranquilidade, cada um cumprindo o caminho traçado, sem corre-corre, sem gritos e sem confusão. Assim sucede nos intervalos das aulas e no seu recomeço, na hora do almoço e nas salas de aula durante as aulas. O silêncio faz parte da rotina das escolas. Em duas delas, o silêncio, no horário das aulas, era tanto que os pesquisadores pensaram que era dia feriado, portanto, sem a presença de alunos.

Assim sendo, é consequência constatar que não há violência nessas escolas, nem necessidade de mecanismos de disciplinamento e punição. Tudo flui da maneira ordeira, prevista e planejada. Não há violência na escola e nem no seu entorno próximo. A localização dessas escolas talvez explique esse fenômeno. Não são escolas de bairro. Elas estão situadas no centro das cidades e recebem alunos de vários bairros ou distritos, o que pode permitir que se evite a reunião e o combate de gangues nas escolas. Também nessas escolas, e talvez pela mesma razão, juntamente com a qualidade dos alunos e de suas famílias, embora não se tenha notado diferenças na composição dessas famílias, desconhece-se o uso de drogas.

A localização das escolas e o seu impacto sobre a aprendizagem dos alunos têm sido variáveis estudadas há algum tempo, mas, recentemente, algumas contribuições interessantes foram elaboradas por Érnica e Batista (2012, p. 642), quando mostram que "as metrópoles objetivam e reificam as desigualdades socioeconômicas que as caracterizam na organização de seu espaço, sob a forma de segregação espacial" e que

as escolas situadas em territórios de alta vulnerabilidade acumulam desvantagens e tendem a se consolidar como locais de "decantação" dos diversos problemas das escolas em posição de vantagem. 
As escolas de meios vulneráveis tendem, em primeiro lugar [...], a concentrar alunos com baixos recursos culturais familiares. Dada sua localização em regiões periféricas e de grande vulnerabilidade social, tampouco a matrícula nessas escolas tende a ser atraente para famílias com maiores recursos culturais e que não vivem no entorno imediato da escola (Ibidem, p. 656).

\subsection{Tempo letivo}

A motivação dos alunos para a aprendizagem e a internalização da necessidade da disciplina contribuem significativamente para que o tempo letivo seja quase que totalmente cumprido. As nove aulas diárias de 50 minutos utilizam uma média de 45 minutos de tempo de ensino. Já que os alunos não vagam pelos corredores e se dirigem de maneira imediata para as salas de aula após os intervalos, e não há indisciplina dentro de sala de aula, não há descontinuidade no tempo de ensino. O professor pode logo iniciar a aula e aplicar a metodologia que julgar conveniente. Não há perda de tempo, descontada a tradicional chamada.

A importância do tempo letivo talvez não seja suficientemente destacada em pesquisas e análises da qualidade da aprendizagem e suficientemente levada em conta na elaboração de políticas educacionais. Ao contrário, os pesquisadores consideram o tempo letivo uma variável absolutamente relevante: como aprender se não há tempo adequado de ensino? É comum constatar que nas escolas o tempo letivo é diminuído pelos mais diversos motivos que vão desde o retardo em ganhar a sala de aula, a indisciplina dentro da sala de aula, os feriados constantes por motivos absolutamente desnecessários e desrespeitosos à função escolar (festa da escola, aniversários do diretor, da padroeira, shows na cidade, pároco ou prefeito usando a escola para outros fins, etc.), as greves, os desastres, a liberação dos alunos após provas ou por motivos fúteis, etc. Poucas escolas utilizam de 40 a 45 minutos, dos 50 previstos, com um ensino efetivo. A pesquisa Tallis, realizada em 2013, mostrou que "os professores brasileiros são os que reclamam passar mais tempo mantendo a ordem em sala de aula $(19,8 \%)$ entre todos os professores participantes da pesquisa" e que no Brasil também se "observa o maior percentual médio de tempo gasto com tarefas administrativas em sala de aula, por exemplo, registrando frequência, distribuindo informativos e formulários da escola (12,2\%)" (INEP, 2014, p. 18).

\subsection{Tempo integral}

O quadro de tempo efetivamente dedicado ao estudo se completa nas escolas estudadas pela adoção do tempo integral em quatro das cinco delas. Mais uma 
vez a escola militar se diferencia das outras, já que adota o regime de um turno para alunos do $1^{\circ}$ e $2^{\circ}$ anos. Desta forma, as quatro escolas funcionam das $7 \mathrm{~h} 10 \mathrm{da}$ manhã às $16 \mathrm{~h} 40$ da tarde, um regime de nove aulas diárias, com o almoço servido no próprio estabelecimento. Além disso, a pesquisa apurou junto aos alunos, aos professores e ao núcleo gestor, de forma unânime, que tarefas são passadas para um estudo noturno caseiro de, em média, uma hora e meia. Tudo isso pode parecer muito, e até excessivo, mas nem os alunos, nem os professores se queixam e julgam demasiado o tempo pedagógico. Vale assinalar, ainda, a quase inexistente evasão de alunos. Ela ocorre em pequeno número nas escolas profissionalizantes, quando o aluno não consegue escolher o curso técnico desejado, não se adapta aos dois turnos, é reprovado, não consegue acompanhar o ritmo do ensino, os pais mudam de bairro ou município. A reprovação pode significar um abandono da escola já que não poderão acompanhar a turma com aquele curso em que estão matriculados. Infere-se que o abandono ou evasão seja inferior àquela encontrada em escolas públicas comuns, mas não há números cabais a apresentar. Muitas vezes os dirigentes dessas escolas falam em "inadaptação" em vez de evasão.

\subsection{Estágio}

As três escolas profissionalizantes que, além de ministrar o currículo do Ensino Médio comum a todas as escolas do mesmo nível, preparam para uma determinada profissão técnica, ainda acrescentam um instrumento de qualificação do aluno: um estágio, conforme prevê a legislação. Os alunos do segundo semestre do $3^{\circ}$ ano fazem um estágio remunerado numa empresa selecionada no ramo da especialização. O estágio é supervisionado e ocupa um turno; além de experiência e consolidação dos conhecimentos, os estagiários recebem meio salário pago pelo governo do Estado. O momento do estágio coincide com o período final de preparação para a prova do Enem, o que representa um acúmulo de trabalho e tarefas para os alunos, mas todos encaram a situação com normalidade, uma vez que o estágio é visto pelos alunos e professores como instrumental para uma maior qualificação do alunato. Estágio, tempo integral na escola, tarefas noturnas, tempo de aulas cheio, autodisciplina e desejo de aprender em função de uma mobilidade social podem explicar que alunos de baixa renda apresentem resultados de desempenho satisfatórios. Mas essas características não explicam tudo.

\subsection{Núcleo gestor: eixo pedagógico e planejamento}

Evidentemente que os fatores de qualidade descritos até o momento não agem independentemente uns dos outros, mas se superpõem uns aos outros e criam uma organicidade dinâmica. $\mathrm{O}$ desejo de aprender e a disciplina, por exemplo, liberam o núcleo gestor para cuidar do essencial: a atenção pedagógica. Conversando e 
entrevistando o núcleo gestor das escolas ficou enfatizado que a principal tarefa era o binômio ensino-aprendizagem, e que não havia tarefa mais importante. A fala dos dirigentes era totalmente voltada ao aspecto pedagógico e didático, sobretudo após as escolas terem acrescentado a seu quadro de servidores a presença de um auxiliar financeiro. Uma consequência disso é a existência de um efetivo planejamento das atividades acadêmicas e uma organização administrativa voltada para a tarefa pedagógica da escola. A uma disciplina suave e efetiva, se junta, nessas escolas, uma organização cuidadosa e um planejamento participativo do núcleo gestor com os professores, o que produz uma grande sintonia entre os dois grupos.

\subsection{Professores}

Os professores, como mencionado acima, ostentam a mesma qualificação da dos colegas de escolas regulares (Licenciatura e/ou Bacharelado, Especialização e, remotamente, Mestrado) e recebem os mesmos salários de acordo com a qualificação e o tempo de serviço. Aos professores das escolas profissionalizantes, foi prometida uma gratificação que não foi paga até o momento dessa pesquisa. Mas, seguramente, as condições de trabalho dos professores que trabalham em quatro delas (a escola militar novamente deve ser diferenciada) são peculiares. Em primeiro lugar, a maioria dos docentes trabalha numa única escola e, isso, em tempo integral, o que traz uma série de consequências, desde o tempo de dedicação ao ensino, o tempo de planejamento e preparo das aulas, o conhecimento e o entrosamento com os alunos e, surpreendentemente, um acúmulo de trabalho e um aumento da responsabilidade. O efeito surpresa ficou por conta dos pesquisadores diante dessa situação. Os professores foram unânimes em declarar que a carga de trabalho aumenta quando se trabalha em tempo integral numa única escola cujos alunos também estudam em tempo integral, o que pode explicar o sucesso de tais escolas em termo de aprendizagem. Todos trabalham mais, alunos e professores, e aderem ao mesmo projeto e, por isso, a responsabilidade aumenta. Os professores almoçam juntamente com os alunos e, durante o tempo reservado à refeição, não deixam de ser professores, ou seja, continuam em situação de trabalho. Outra maneira de conferir esse dado é constatar que são poucos os professores que se candidatam a um posto nessas escolas, e que muitos desistem, preferindo trabalhar em escolas menos rigorosas, isto é, escolas que exigem menos dedicação e menos trabalho. Outro fator diferenciador é que os professores convivem e colaboram com professores de disciplinas variadas, já que três escolas operam tanto no Ensino Médio regular quanto em especialidades técnicas. Os professores reagem positivamente com esse entrosamento, que julgam enriquecedor.

Poucos professores exercem outra atividade, o que significa que o ensino desses professores não é marginal nas suas vidas, mas se constitui em uma profissão 
levada a sério, embora mal remunerada e incerta, já que muitos são contratados como temporários, o que pode obrigar a interromper o trabalho docente em vista de um emprego melhor. Há, portanto, a possibilidade de interrupção da dedicação à escola. Pesquisa recente da organização Todos Pela Educação, analisando dados do MEC/Inep - Prova Brasil/Saeb (BRASIL, 2008), revela que $41 \%$ dos professores da Educação Básica fazem jornada extra para compor a renda, o que demonstra a boa situação dessas escolas, já que poucos professores exercem outra atividade, como foi apontado acima. Esses professores, todavia, dizem sentir necessidade de aperfeiçoamento dirigido para a eliminação de lacunas da formação e a adaptação às novas exigências de conhecimento. Apesar disso, o nível de satisfação com a profissão, a escola e os alunos é alto, o que também é manifestado pelos pouquíssimos atrasos e faltas ao trabalho, e pelo entusiasmo expresso nas entrevistas e nos questionários.

\subsection{Cultura Interna das Escolas}

Talvez fosse possível resumir o que foi descrito até o momento com o uso da categoria "clima escolar".

$\mathrm{Na}$ literatura sobre fatores associados ao sucesso escolar tem sido recorrente o entendimento de que o clima escolar, ou seja, "a cultura interna das escolas" (Cunha; Costa, 2009) é um dos elementos que favorecem o êxito de estudantes. Estudos realizados na América Latina reiteram que, ao lado de outras variáveis, este é um elemento-chave de efetividade em nível da escola - o clima positivo é traduzido como um ambiente agradável e favorável à aprendizagem, onde professores e alunos estão à vontade, vivenciando um entorno ordenado e tranquilo, compartilhando normas sobre o uso do tempo e disciplina (RACZYNSKI; MUÑOZ, 2006, p. 280, apud VIDAL; VIEIRA, 2014, p. 35).

As autoras ainda acrescentam a definição de clima escolar dada por Cunha e Costa (2009, p. 2): "conjunto das expectativas recíprocas compartilhadas pelos agentes do espaço escolar", o que parece ser o caso das escolas aqui analisadas, visto que os sujeitos escolares demonstram coesão em torno dos objetivos da escola, da aprendizagem e da disciplina principalmente.

\subsection{Deficiências e obstáculos à aprendizagem}

Tudo, todavia, não é perfeito nessas escolas, como se poderia esperar. A pergunta que dirigiu a pesquisa quanto às deficiências e aos obstáculos foi a seguinte: 
o que falta ou poderia ser feito para melhorar os resultados acadêmicos de cada escola? Entre o núcleo gestor e os professores, a resposta, tanto nas entrevistas quanto nos questionários, foi o precário nível de aprendizagem que os alunos adquirem no Ensino Fundamental. Há, com efeito, um grande obstáculo a uma melhor aprendizagem nessas escolas públicas de Ensino Médio, que é a baixa qualidade do Ensino Fundamental cursado pelos alunos. A quase que totalidade deles, com exceção dos alunos da escola militar, cursou o Ensino Fundamental em escolas públicas municipais, que, muitas vezes, oferecem um ensino precário que não prepara para o Ensino Médio. Xavier e Alves (2015), ao falarem sobre o problema do desempenho escolar, afirmam que

esse fenômeno passou a ser investigado pela análise da exclusão intraescolar. Essa noção caracteriza a situação do aluno matriculado na escola, mas cujo desempenho escolar é insuficiente para a série que ele cursa. A exclusão intraescolar não ocorre simplesmente pela dificuldade de acesso ao sistema escolar ou pela evasão deste. Ela informa sobre a ausência de aprendizado dentro da escola (XAVIER; ALVES, 2015, p. 222 apud SOARES et al., 2012).

Ao concluir o Ensino Fundamental, o aluno sabe o que deveria ter aprendido ao fim da primeira etapa desse mesmo nível de ensino. As escolas tentam compensar com um processo de seleção, que, segundo os mesmos entrevistados, não é satisfatório, sendo necessário encontrar uma melhor fórmula para realizálo, e, sobretudo, por um semestre de nivelamento, que se mostra insuficiente. A situação permanece delicada, já que melhorar o Ensino Fundamental não está, evidentemente, ao alcance dessas escolas e da rede estadual. O obstáculo é, portanto, difícil de ser superado e arrisca ser permanente se não houver uma reação dos diversos municípios encarregados do Ensino Fundamental.

O despreparo dos alunos que chegam às escolas exige um trabalho redobrado dos responsáveis e professores e, certamente, contribui para a diminuição da qualidade dos resultados acadêmicos. Essa dificuldade, a falta de base, é, declaradamente, o grande entrave das escolas. Pode-se dizer que o despreparo mina os esforços da escola por dentro, de maneira imperceptível, um pouco como o cupim enfraquece madeiras que suportam um telhado.

\subsection{Infraestrutura}

O estudo de Abrúcio (2010, p. 263) reconhece que a infraestrutura das escolas exerce "efeitos sobre os resultados acadêmicos dos alunos". Se a infraestrutura das escolas pesquisadas deve ser considerada boa em comparação com a grande 
maioria das escolas públicas do Ensino Médio, ela não é satisfatória nos dizeres dos professores, do núcleo gestor e dos alunos. Mesmo havendo quadra poliesportiva coberta, laboratórios de informática e de Ciências e salas de multimeios, eufemismo para designar bibliotecas com poucos títulos e sem bibliotecários formados, o conjunto da comunidade escolar clama por mais espaço e melhor manutenção dos estabelecimentos em geral e, principalmente, das salas de aulas, que são pequenas, muitas sem refrigeração e, nitidamente, precisando de pintura. A manutenção é difícil porque depende da Seduc, de sua burocracia e de sua penúria de recursos financeiros. De fato, todos se queixam de falta de autonomia da escola para operar o planejamento, o gerenciamento e a manutenção. Quanto a ter uma escola mais ampla e mais adequada às necessidades pedagógicas, tudo depende de decisões da Seduc, senão do governador.

É bom que se diga que o governo de Estado está executando um projeto de construção de novas escolas profissionalizantes espalhadas em diversos municípios. Entre as escolas pesquisadas, nenhuma pertence a esse grupo de edifícios recém-construídos.

\subsection{Artes e esportes}

Quando se pensa em escolas de tempo integral, geralmente tem-se em mente um turno reservado a aulas e estudos e outro, a atividades diversas, incluindo artes e esportes. Não é o caso das cinco escolas pesquisadas. A escola militar, como foi dito, trabalha em turno único; outra escola tem dois turnos de estudos regulares em sala de aula, e três dividem os dois turnos entre o currículo comum ao Ensino Médio e a formação técnica, havendo somente as aulas curriculares de Educação e Artes e Educação Física. Não se observa nenhuma ênfase nas artes e nos esportes (aliás, há uma ausência total de equipamento e instrumentos artísticos e esportivos) e ninguém parece sentir falta disso, já que essa ausência não foi notada ou apontada por nenhum integrante das escolas. A falha, se falha houver, é de concepção, já que nada foi previsto nesse sentido. Também não se imagina em que momento uma ampliação da formação artística e esportiva poderia ocorrer, já que a jornada escolar ocupa todas as manhãs e tardes, entrando na noite.

Assim se completa o quadro sinóptico de cinco escolas públicas cearenses. Sem dúvida, elas constituem um avanço extremamente significativo e destoam amplamente das ideias correntes aceitas a respeito das escolas públicas e de seus projetos pedagógicos. No meio de um mar de descrédito da escola pública brasileira, elas representam um progresso inquestionável, capaz de atrair filhos de famílias da classe média alta, o que poderia ajudar a melhorá-las ainda mais. Assim se vislumbra o fim do apartheid social da escola pública. 
Mas essas escolas não são a única realidade da escola pública de Ensino Médio, tampouco a maioria. Pelo contrário, elas se distinguem nitidamente da grande maioria das escolas que podemos chamar de "escolas regulares, comuns ou ordinárias", que povoam o universo escolar cearense. Para cinco delas nos voltamos agora, na segunda parte de nosso díptico.

\section{Caracterização de escolas de baixo desempenho escolar}

Sem risco de errar, é possível afirmar que essas escolas representam o reverso do primeiro grupo acima caracterizado. Chamaremos essas escolas de "escolas comuns ou regulares". Antes, porém, é necessário comentar que a caracterização a seguir somente se aplica a quatro das cinco escolas estudadas, já que a Escola do Campo está longe de apresentar as mesmas características das outras, embora seus alunos tenham rendimentos acadêmicos também muito fracos. Ela é, com efeito, uma escola que caminha para ter dois turnos, com uma belíssima infraestrutura e uma programação sui generis voltada para a formação agrícola de seus alunos, filhos, na sua maioria, de famílias assentadas e com renda abaixo de dois salários mínimos ou de filhos de fazendeiros. Ao Ensino Médio comum ensinado num turno, é acoplada, no segundo turno, uma formação no Projeto Mandala que inicia a técnicas agrícolas adaptadas à terra semiárida, visando reter os jovens no meio rural. O grande empecilho da louvável iniciativa é que $100 \%$ dos alunos consultados não querem permanecer no meio rural, sendo atraídos por profissões e trabalhos em cidades. Como a escola é recente, completando três anos, e possui um alunato homogêneo e disciplinado, professores do município e administração da Seduc, com a ativa participação de uma central trabalhadora, é provável que, nos próximos anos, o rendimento escolar melhore, mesmo que os alunos não pensem em permanecer no campo. Em outras palavras, essa escola não padece das características inibidoras de aprendizagem das outras quatro escolas.

\subsection{Os alunos não desejam aprender}

Quem está acostumado a lidar com professores da rede pública escuta constantemente o refrão que os alunos não querem nada, o que, muitas vezes, leva o observador a desconfiar do interesse desses docentes em ensinar. No entanto, essa pesquisa observou, empiricamente, tanto através das entrevistas, dos questionários e, sobretudo da observação in loco, que de fato os alunos não manifestam nenhum desejo sólido de aprender; não manifestam nenhum entusiasmo com sua presença na escola e não estão preparados para manter esforços contínuos de trabalho escolar. Eles declaram frequentar a escola para encontrar amigos e passar o tempo, não para estudar e aprender, portanto. Estudar para eles significa 
simplesmente ir à escola, ato físico, e não se dedicar à aprendizagem dentro e fora da sala de aula, como em casa por exemplo. Um indicador interessante dessa postura é que muitos não levam sequer os livros para a escola, já que "são pesados", conforme relatam. Isso significa que não se interessam pelos livros, não os leem e os consultam pouco.

Os alunos dessas escolas não manifestam desejos em aprender e não conseguem ver a importância da escola em suas vidas, já que pouco delas esperam. De qualquer maneira, eles não estão dispostos a se empenharem nos estudos. Sinal disso é que poucos afirmam o desejo de continuarem os estudos além do Ensino Médio e candidatarem-se ao Ensino Superior, tampouco, pensam em ter uma formação técnica. Dizem pretender trabalhar, sem especificar qual trabalho serão capacitados a realizar, e não manifestam o desejo de se inscreverem em um Curso Técnico. Irão, portanto, enfrentar o mundo do trabalho somente com o certificado do Ensino Médio, sem nenhuma profissão definida, isto é, sem uma identidade trabalhista.

Há, portanto, uma enorme falta de motivação acadêmica nesses alunos o que cria um grande problema pedagógico. Como ensinar a alunos que não querem aprender ou, pelo menos, não estão dispostos a se dedicar aos estudos? Todas as teorias pedagógicas desde Sócrates realçam que a admiração diante das coisas e o desejo de questionar e aprender é postura sine qua non para um ensino bem-sucedido. Entre nós, Paulo Freire desenvolveu um método baseado em "criticidade, protagonismo, curiosidade e criatividade" (BRAGA, 2015), considerando que a aprendizagem logra êxito se houver desejo e empenho. A questão primeira dessas escolas passa, então, a ser: como motivar os alunos a aprender? Ainda mais que, nessa tarefa, os mestres pouco podem contar com os pais, que não participam da vida escolar dos próprios filhos e, ainda menos, da escola. Aqui, certamente reside a causa primeira e essencial do baixo rendimento de ensino-aprendizagem nessas escolas. Esse é o entrave principal a ser vencido, pois reflete, sobretudo, o que ocorre na escola: desde a disposição dos mestres e do núcleo gestor até o comportamento de parte dos alunos, o que prejudica, inclusive, aqueles desejosos de receberem uma boa formação. Deve ser a grande preocupação da Seduc, dos educadores, dos pesquisadores e de todos os interessados no processo educacional: como motivar para o estudo os filhos das classes mais carentes da nossa sociedade? Quais tipos de escola, atividades, currículo, pedagogia, tecnologia, calendário, etc., devem ser implantados? Além de desmotivados, os alunos das cinco escolas pesquisadas se revelam despreparados para cursar o Ensino Médio, já que desde cedo manifestaram esta falta de disposição para o estudo e estudaram em escolas de Ensino Fundamental públicas de baixa qualidade. 


\subsection{Indisciplina}

A primeira e mais visível consequência da falta de desejo de aprender é o clima de indisciplina nas escolas. A constatação não é nova; ela é até repetitiva, costumeira. Assim, uma pesquisa recém-realizada em escolas do maciço de Baturité relata a indisciplina dos alunos e a dificuldade de trazer as famílias dos indisciplinados para discutir o problema com a escola, como relatam Vidal e Vieira (2014). Mas como se manifestou a indisciplina ao longo de nosso estudo?

Primeiro, pelo ambiente barulhento e agitado das escolas, logo percebido ao entrar no recinto escolar. Mesmo durante as aulas, as salas de aula são "bagunçadas", como falam e escrevem os alunos respondendo aos questionários. O ruído das salas invade outras salas e os corredores, ao ponto em que o visitante se pergunta como é possível ensinar em tal situação. Geralmente, há alunos perambulando pelos corredores, não raramente conversando em voz alta, como se estivessem em pleno recreio. Se houver um ou mais professores faltando, os corredores e o pátio se enchem de alunos desocupados e barulhentos, muito dessa situação sendo causada por uma falta alarmante de espaço, não tendo os sem-aula onde ficar.

Talvez, o depoimento mais significativo de toda a pesquisa foi dado por um diretor de uma dessas escolas quando afirmou: "Minha função aqui se resume a 'tanger' os alunos para dentro da sala de aula". E ele não estava exagerando. Constantemente, há membros do núcleo gestor, funcionários ou professores "empurrando" os alunos para que, depois dos intervalos das aulas e do recreio, eles retornem para a sala de aula. Esse desabafo constrangido do diretor expressa um estado de coisa totalmente contrário ao espírito pedagógico necessário, e explica em parte o insucesso ou fraco desempenho das escolas. Talvez, mais do que indisciplina, devamos falar em falta de ordem ou organização provocada pelo desinteresse dos alunos e a infraestrutura das quatro escolas.

Surpreendentemente, nem os professores, nem os núcleos gestores acusaram violência e problemas de drogas nas escolas, embora sejam escolas de bairros carentes da periferia onde a violência atinge níveis elevados e há reserva de territórios por gangues inimigas, conforme relataram alguns dos sujeitos. O que chamamos, aqui, indisciplina ou falta de ordem não chega à violência física nem a desacatos verbais aos professores, pelo menos de forma habitual, o que retira uma das explicações muitas vezes dadas pela baixa qualidade de nossas escolas. De qualquer maneira, a falta de disciplina, ordem e organização, qualquer que seja o conceito adequado, impacta todas as atividades da escola e o ânimo de todos. 


\subsection{Tempo letivo}

Uma das consequências mais severas para a aprendizagem é a erosão do tempo letivo. Há unanimidade nas entrevistas e nos questionários em declarar uma perda de 20 a 25 minutos de tempo letivo por aula de cinquenta minutos. Isto é, em torno da metade do tempo previsto de aulas se encontra desperdiçado. Alunos, em sua maioria sem desejo de aprender, "tangidos" contra a sua vontade para dentro da sala de aula, sem livros didáticos que julgam demasiado pesados para levar da casa para a escola. Essa soma de características pode ajudar a explicar os baixos resultados acadêmicos, visto que se percebe a falta de priorização dos estudos. Para complementar o cenário destacado, os professores ainda relatam que não passam lições de casa, o que contribui para afastar os alunos dos livros.

Os autores deste trabalho vêm insistentemente chamando a atenção nesse componente das escolas, já que captaram essa realidade em outras pesquisas, como em Pessoa (2009), e em outras atividades de escuta da realidade escolar.

O silêncio é outra condicionante da aprendizagem. A rede estadual e ainda menos as escolas não possuem um sistema de substituição na ausência de um professor. Os alunos ficam ao léu, num espaço restrito, na espera da próxima aula. Então, o barulho aumenta e atrapalha as aulas em andamento. Escolas fisicamente sem espaço e barulhentas dificilmente podem ter uma aprendizagem de qualidade.

\subsection{Escola de turno único}

Outra característica dessas escolas, novamente com exceção da escola do campo, é que elas funcionam em um só turno, com cinco aulas diárias oficialmente. É muito pouco para qualquer aprendizagem séria e, ainda menos, para escolas com as características que estamos apontando, ainda mais considerando o grande número de interrupção das aulas ao longo do ano e o baixo aproveitamento do tempo letivo, como foi apontado anteriormente. Na década de 60, do século passado, sob a liderança do governador do Rio de Janeiro, Leonel Brizola, e de Darcy Ribeiro, implantou-se o tempo integral, mas a ideia não prosperou. Hoje, o discurso é retomado e muitos políticos prometem escolas em tempo integral. O tempo integral é, certamente, um fator de melhor rendimento escolar, desde que as escolas ofereçam condições necessárias de funcionamento, a começar pelo desejo de os alunos estudarem, e de os professores trabalharem e ensinarem em dois turnos na mesma escola. Sem essas condicionantes mínimas, o tempo integral pode não dar os resultados esperados e aumentar os custos pessoais e financeiros em vão, tornando inócua uma política que, com condições adequadas, poderia ter um grande impacto sobre a qualidade escolar. 


\subsection{Núcleo gestor e professores}

Essas escolas apresentam uma ambiguidade. Os pesquisadores encontraram núcleos gestores e professores interessados e até entusiasmados, dedicados a seu trabalho e preocupados com o aspecto pedagógico da escola. Os fracos resultados escolares levavam a supor certo abandono dos responsáveis das escolas. Mas isso não se verificou, embora esse ponto precisasse ser mais aprofundado nos afazeres do cotidiano das escolas. Nem as visitas, nem as entrevistas e nem os questionários expressam um desleixo e uma desistência dos dirigentes e dos professores de ensinar. A falta de entusiasmo dos alunos pela aprendizagem certamente pesa sobre os dirigentes e os professores e os impede de impor um ritmo mais fecundo a seu trabalho, o que pode provocar desânimo. Como foi dito anteriormente, o núcleo gestor desperdiça muito de seu tempo "tangendo" os alunos do que em preocupações pedagógicas e didáticas. A indisciplina rouba muito das energias dos dirigentes e mestres. E, de fato, como fazer de outra maneira?

Nota-se, portanto, um interesse e uma satisfação pela profissão, mesmo em uma situação de grande dificuldade. Em três escolas, todavia, os professores se declararam despreparados para o exercício da profissão, a afirmação sendo corroborada pelos respectivos núcleos gestores. Forma-se, assim, um círculo perverso: o aluno não quer estudar e o professor não se sente preparado para a tarefa, que ele executa num ambiente inadequado, senão hostil. E ainda se pode acrescentar numa situação profissional instável, pois a grande maioria dos docentes é contratada de forma precária, como professor temporário em condições de trabalho nitidamente vexatórias ${ }^{1}$.

A situação do professor temporário precisa ser melhor equacionada. Ela cria uma insegurança na escola e multiplica as chances de um rodízio de professores absolutamente nocivo ao ensino e à aprendizagem, além de desviar o núcleo gestor de suas funções, perdendo tempo em busca de um novo professor, que também será temporário e assim por diante. Também há necessidade urgente do sistema montar um programa de professores substitutos para preencher as faltas dos professores. A falta de um professor numa escola descontrola toda a rotina escolar, prejudicando a todos.

\footnotetext{
O professor temporário na rede estadual do Ceará se encontra num vazio de direitos, visto que não possui nenhum tipo de vínculo empregatício com o governo do Estado. A contratação é regida pela Lei Complementar $n^{\circ} 22 / 2000$ (CEARÁ, 2000). Essa lei mostra a precariedade do vínculo, a saber: o contrato pode expirar ou ser rescindido "sem direito a indenização" (Arts. $6^{\circ}$ e $7^{\circ}$ ), como seguro-desemprego, por exemplo. Ademais, o vínculo é através de contrato que tem duração máxima de 12 meses, tendo o professor que conviver com as incertezas em ter seu contrato renovado após esse período. Por fim, esse indivíduo não tem direito ao Plano de Cargos, Carreiras e Salários da categoria, o que significa que independentemente de sua titulação ou tempo de serviço receberá a mesma quantia pela hora-aula, que é um valor inferior ao da hora-aula do Nível 1 daquele Plano. Atualmente, cerca de $45 \%$ dos docentes da rede estadual do Ceará se encontram nessa situação.
} 


\subsection{Infraestrutura e pobreza das escolas}

Quatro das escolas pesquisadas apresentam uma estrutura nitidamente insuficiente e indigna. Elas são pequenas, baixas, apertadas, isto é, sem espaço, escuras, quentes e até parecem mais depósito do que escola. A infraestrutura não oferece nenhum atrativo, embora todas possuam laboratórios básicos de ciências (visivelmente pouco utilizados) e de informática, quadra coberta e biblioteca (as salas multimeios, com acervo pequeno, são os locais mais acolhedores e leves das escolas). Mas tudo é tão comprimido que o ambiente se torna opressor. Assim são as salas do núcleo gestor, dos professores, do diretor de turma, de aula e os banheiros. Obviamente que, nesses locais, todo barulho é amplificado e que há um sentimento de opressão e não de liberdade e libertação. O ambiente é cansativo e estressante. Sem falar que todos os espaços precisam de manutenção. Na realidade essas escolas deveriam ser reconstruídas com uma outra arquitetura e muito mais espaço, abrindo horizonte, claridade e acolhimento. Um ambiente onde seja bom ficar.

Mas ainda são escolas pobres que se resumem a um mínimo para abrigar professores e alunos na esperança que desse ambiente possa surgir uma aprendizagem. Essas escolas, a exemplo de todas as pesquisadas, não oferecem esportes, nem artes de maneira consistente. Elas não possuem instrumentos musicais (onde poderiam guardá-los?), e nem há espaço para dança, artes plásticas, etc. Não há esportes organizados, campeonatos internos ou externos, intercolegiais, por exemplo. Há somente aulas curriculares de educação e artes e de educação física. A estrutura da escola está mais propícia a expulsar o aluno do que a atraí-lo.

\subsection{Cultura interna ou clima escolar}

Fica fácil deduzir, do que foi exposto, que o clima escolar dessas escolas é pobre e não manifesta nenhuma cumplicidade com um local de ensino e aprendizagem de qualidade. Há um acúmulo de fatores negativos que ocultam aspectos positivos como as disposições favoráveis dos núcleos gestores, dos professores e de parte dos alunos, e impedem-nos de serem dominantes. O que se pode dizer é que essas escolas não exalam um ambiente de estudo; pelo contrário, muitas variáveis militam para debilitar o clima escolar. Assim, a falta de vontade de aprender e estudar, a indisciplina, o barulho na escola e a "bagunça" na sala de aula, o pouco tempo letivo, o despreparo de professores, as condições de trabalho, o ensino de um turno, a pobreza das escolas e sua péssima infraestrutura estão a anular os reais esforços didáticos dos professores e a puxar para baixo o rendimento escolar, o que faz que essas escolas sejam tristes. 


\section{Conclusões}

Pelas descrições realizadas a partir da amostra de dez escolas selecionadas para este estudo, observa-se que a mesma rede escolar está marcada por um profundo dualismo, uma intensa estratificação, uma falta de equidade e dois tipos ou modelos de escola incompatíveis entre si. Esse dualismo se, por um lado, desmente a crença de senso comum e amplamente difundida de que todas as escolas públicas são de má qualidade, por outro, levanta sérios questionamentos sobre a qualidade de escolas públicas. A verdade é que as médias no Enem das melhores escolas públicas ainda são inferiores às médias das melhores escolas privadas frequentadas por filhos de famílias das classes assim chamadas de A e B, o que não poderia ser de outra forma, já que o sistema escolar cearense e brasileiro é um sistema de classe. As escolas particulares mercantilistas recebem filhos e filhas das classes médias e altas escolarizadas e abastadas; as escolas públicas, filhos e filhas de famílias de classe média baixa, trabalhadora ou excluída. Essa característica não é propriamente brasileira. Pesquisas internacionais concluem que alunos de famílias socioeconomicamente privilegiadas aprendem melhor; somente uma parte dos alunos de famílias desfavorecidas consegue ter sucesso (6\%), conforme já destacado. A qualidade da escola pública, mesmo em países ricos, varia segundo a renda das famílias de bairros de uma mesma cidade. O Ceará não é exceção a essa realidade.

Assim, ficam duas perguntas cujas respostas devem ser traduzidas em políticas efetivas. A primeira, como melhorar ainda mais o rendimento das escolas com bom desempenho no Enem? Vimos que os que fazem essas escolas apontam a necessidade de ter um Ensino Fundamental de melhor qualidade para que os alunos cheguem ao Ensino Médio melhor preparados. Além disso, os professores precisam ter a sua autoestima elevada e sentir-se valorizados, inclusive por formação continuada e específica de acordo com suas deficiências individuais. Para isso, certamente duas lacunas devem ser equacionadas de forma definitiva: a necessidade de um sistema eficiente de professores substitutos para que os titulares possam se aperfeiçoar sem prejuízo da continuidade da aprendizagem dos alunos e a figura do professor temporário deve ser eliminada ou repensada. $\mathrm{Na}$ situação atual, ela é um sério obstáculo à sustentabilidade dos estudos dos alunos e da organização da escola.

Há que destacar ainda um terceiro fator que se refere à infraestrutura dos prédios escolares e ao uso pedagógico e competente de laboratórios mais especializados e de novas tecnologias, o que significa uma ênfase em competências específicas dos professores. Mas certamente há aqui variáveis ocultas, como o baixo nível de escolarização e de cultura culta das famílias de baixa renda. Entre essas variáveis 
importa destacar o uso da língua culta, aquela ensinada na escola, mas que não é praticada no dia a dia familiar dos alunos. Existe, portanto, um hiato entre a cultura escolar e a cultura familiar, o que não ocorre com alunos das classes médias mais altas.

Pesquisas perscrutando a dimensão pedagógica a partir da sala de aula poderão dar subsídios a políticas específicas alinhadas com as reais necessidades expressas pelo ambiente escolar. A referência aqui diz respeito a estudos acompanhando a gestão escolar, o desenrolar do tempo letivo em sala de aula; as metodologias dos professores no preparo e na execução das aulas e os métodos de estudo dos alunos; a adequação e o uso do material didático, dos laboratórios e das novas tecnologias; as metas e seu cumprimento por parte da escola e tantos outros assuntos que perpassam o dia a dia da vida escolar.

Mas a segunda e crucial interrogação lançada por essa pesquisa diz respeito ao que fazer com as escolas de fraco desempenho escolar. A resposta não é evidente. Poder-se-ia perguntar se se trata, principalmente, de uma questão social ou de uma questão pedagógica, o que equivaleria a perguntar o que a escola pode fazer em ambientes tão desfavoráveis à aprendizagem? A pesquisa insistiu em destacar que os alunos dessas escolas possuem um interesse muito baixo pelo estudo e pela aprendizagem. Muitas vezes questionamos: ao aceitar essas evidências não se estaria "culpando as vítimas" e inocentando o sistema escolar e a sociedade? Não há dúvida quanto à vitimização dos adolescentes e dos jovens adultos, mas não pelos pesquisadores. Eles são vítimas de uma sociedade profundamente dividida em classes e de uma cultura resultante desse apartheid. Nesse sentido, o problema é social e os alunos dessas escolas somente reproduzem a cultura de sua classe, de seu grupo e de suas famílias, que são carentes econômica, social, cultural e escolarmente. É nesse contexto que se deve perguntar o que a escola pode fazer para modificar o jogo, mesmo sabendo que ela é uma instituição reprodutora da realidade social. Poderia ela intervir? Se a resposta for sim, o que deve fazer?

A primeira condição é que as escolas sejam um atrativo para os adolescentes; isto é, que elas sejam um lugar onde os adolescentes achem bom estar e onde eles possam manifestar e realizar suas aspirações e habilidades. Uma escola voltada para o desenvolvimento individual de seus alunos. Isso é tudo o que as escolas estudadas não são, a começar pelo prédio!

Embora o prédio não seja tudo, ele deveria ser espaçoso e permitir concomitantemente atividades diversificadas, sem que uma intervenha negativamente na outra. $\mathrm{O}$ espaço confinado obriga a atividades repetitivas e sem atrativo para os alunos que já chegam com pouca disposição ao estudo. As salas de aulas, os laboratórios, o pátio 
e a cantina são pequenos e contíguos. Além do mais, essas escolas oferecem pouco ao aluno. Os esportes, as artes, as competições são raros, quase inexistentes. Evidentemente muito há que se fazer também em termos de professores substitutos, professores temporários, metodologia de trabalho, condições e valorização de trabalho dos docentes e outros assuntos abordados anteriormente. Será ainda preciso fazer com que alunos e professores adotem um posicionamento mais crítico e menos acomodado sobre suas escolas de maneira a modificá-las e exigir transformações. Atualmente, a escola de tempo integral volta a ser considerada a solução para todos os problemas da escola pública. Mas é preciso avaliar se a jornada ampliada terá um impacto sobre a motivação dos alunos nas condições físicas, materiais e pedagógicas das escolas. Difícil é imaginar professores e alunos motivados e felizes em escolas gradeadas, barulhentas, sombrias, quentes e sem espaço.

De qualquer forma, a pesquisa deixa uma pergunta a ser discutida e resolvida: o que pode ser feito para que o sistema escolar influa e, se possível, mude a cultura dos alunos e os leve a ter gosto pelo estudo? A partir dessa resposta, Seduc, escolas, núcleos gestores, professores e funcionários terão de aplicar políticas consequentes. A continuar as coisas como estão, será preciso esperar uma reviravolta social para elevar substancialmente a aprendizagem dos alunos. Teremos então que voltar à temática dos anos 60 do século passado: revolução social ou mudanças pedagógicas? 


\section{Ten schools, two quality standards. A research on ten public high schools in the state of Ceará, Brazil}

\section{Abstract}

This paper having as a background the 2011 Enem exams and based on field research conducted in 2013 and 2014 in the state of Ceará, compare five of the ten best scoring public high schools with five of the ten worst performers. Of the ten researched public high schools, four were located in the countryside while six were in the capital. Data collection relied on instruments such as schools visits; interviews with a member of the executive division, teachers, students and staff; and the application of a questionnaire with students and teachers. The objective was to reveal the motives that led to good and poor performance. The collected data sketched a prototype of each school, indicating its main characteristics. Gradually, two mutually exclusive and irreconcilable types, a kind of two ideal types of public high schools, emerged from the research that could help provide insights for future educational policy recommendations. Due to size limits, the article refrained from providing a prototype for each school. Instead, it placed its priority on building the two typologies as a mean to explicit and explain the dualities found between good and poor performers within the same public school system. In the conclusion it contended with issues and debates provoked by the findings.

Keywords: High school education Students 'incentives. School milieu. Educational policies. Inequalities between schools.

\section{Diez escuelas, dos modelos de calidad. Una investigación en diez escuelas públicas de enseñanza media en el Estado de Ceará}

\section{Resumen}

Tomando como base los resultados del Enem del año 2011, se realizó durante el 2013 y 2014, una investigación comparativa en cinco de las diez escuelas de enseñanza media de la red estatal del Estado de CEARÁ que tuvieron el mejor desempeño, y de cinco, entre esas diez, cuyo rendimiento fue el más flojo; cuatro del interior del Estado y seis de la capital. Los procedimientos para lograr reunir los hechos fueron: visitas a las escuelas, entrevistas con un miembro del núcleo gestor, con profesores, alumnos y funcionarios, y la utilización de un cuestionario para un grupo de alumnos y profesores. El objetivo era descubrir qué poseían las escuelas de mejor desempeño y de qué carecían las de rendimiento claramente insuficiente. A partir de los resultados fue constituido un "retrato hablado" de cada escuela, anotando sus principales características. Después, quedó evidenciado que existen dos modelos escolares mutuamente excluyentes e irreconciliables entre sí, lo cual fue determinado en dos tipologías típicamente ideales reveladoras de 
la situación y susceptibles de proveer elementos para la elaboración de políticas educacionales. Este articulo omite los "retratos hablados" de cada escuela por falta de espacio y se limita a la presentación y discusión de las dos tipologías, a fin de explicar y aclarar el doble modelo de dualismo patente, que existe entre las escuelas de una misma red pública. La conclusión origina cuestionamientos provocados por la investigación.

Palabras clave: Enseñanza media pública Motivación de los alumnos. Ambiente escolar. Políticas educacionales. Desigualdad escolar. 


\section{Referências}

ABRÚCIO, L. F. Gestão escolar e qualidade da educação: um estudo sobre dez escolas paulistas. Estudos \& Pesquisas Educacionais, São Paulo, n. 1, p. 241-74, maio 2010 .

BARBER, M.; MOURSHED, M. How the world's best performing schools come out on top. London: Mckinsey and Company, 2007.

BRAGA, M. M. S. C. Prática pedagógica docente-discente: traços da pedagogia de Paulo Freire na sala de aula. Recife: Editora UFPE, 2015.

BRASIL. Instituto Nacional de Estudos e Pesquisas Educacionais Anísio Teixeira - INEP. Desempenho dos alunos na Prova Brasil: diversos caminhos para o sucesso educacional nas redes municipais de ensino. Brasília, DF, 2008.

. Instituto Nacional de Estudos e Pesquisas Educacionais Anísio Teixeira - INEP. Tallis: pesquisa internacional sobre ensino e aprendizagem: relatório nacional. Brasília, DF, 2014. Disponível em: <http://portal.inep.gov. br/web/talis/resultados $>$. Acesso em 18 jul. 2015.

. Ministério da Educação, Conselho Nacional de Educação, Câmara de Educação Básica. Resolução CNE/CEB n ${ }^{\circ}$ 2, de 30 de janeiro de 2012. Define Diretrizes Curriculares Nacionais para o Ensino Médio. Diário Oficial da União, Brasília, DF, seção 1, p. 20, 31 jan 2012.

BRASLAVSKY, C. Dez fatores para uma educação de qualidade para todos no século XXI. São Paulo: Moderna, 2005.

CEARÁ. Lei complementar $N^{o} 22$, de 24 de julho de 2000. Dispõe sobre a Contratação de Docentes, por tempo determinado, para atender necessidade temporária de excepcional interesse público nas Escolas Estaduais.

Disponível em: <http://www.al.ce.gov.br/legislativo/ementario/lc22.htm>. Acesso em: 28 set. 2015.

CUNHA, M. B.; COSTA, M. O clima escolar de escolas de alto e baixo prestígio. In: REUNIÃO DA ASSOCIAÇÃO NACIONAL DE PÓS-GRADUAÇÃO E PESQUISA EM EDUCAÇÃO, 32., 2009, Caxambu. Sociedade, cultura e educação, novas regulações, 2009.

DURKHEIM, É. Regras do método sociológico. 6. ed. São Paulo: Companhia Editora Nacional, 1971. 
ÉRNICA, M.; BATISTA, A. A. G. A escola, a metrópole e a vizinhança vulnerável. Cadernos de Pesquisa, São Paulo, v. 42 n. 146, p. 640-66, maio/ ago. 2012. doi:10.1590/S0100-15742012000200016

MCKINSEY \& COMPANY. Educação: como um sistema escolar de baixo desempenho pode evoluir para tornar-se bom? E como um sistema de bom desempenho pode atingir o nível de excelência? London, 2007. Disponível em: $<$ http://mckinseyonsociety.com/downloads/reports/Education/Education_ Intro_Standalone_Nov24_Portugeuse.pdf $>$. Acesso em: 24 fev. 2011.

MERTON, R. K. Sociologia: teoria e estrutura. São Paulo: Mestre Jou, 1968.

\section{ORGANISATION FOR ECONOMIC CO-OPERATION AND}

DEVELOPMENT - OECD. PISA 2012 results in focus: what 15-years-old know and what they can do with what they know. 2014. Disponível em: $<$ http://www.oecd.org/pisa/keyfindings/pisa-2012-results-overview.pdf $>$. Acesso em: 28 set. 2015.

PESSOA, M. K. M. A influência dos serviços educacionais no desempenho escolar de alunos de escolas públicas e privadas do estado do Ceará: o caso da Fundação Bradesco e do Liceu Vila Velha. 2009. (Monografia de graduação) - Faculdade de Ciências Sociais, Universidade Federal do Ceará, Fortaleza.

RACZYNSKI V., D.; MUNÕZ S., G. Factores que desafiam los buenos resultados educativos de escolas em sectores de pobrea. In: CUENTO, S. (Ed.). Educación y brechas de equidade en America Latina. Santiago: Preal, 2006. Tomo 2, p. 275-352.

SOARES, J. F. et al. Exclusão intraescolar nas escolas públicas brasileiras: um estudo com dados da Prova Brasil 2005, 2007 e 2009. Brasília, DF: Unesco, 2012. (Série Debates ED, n. 4).

VIDAL, E. M.; VIEIRA, S. L. Educação e território: contribuições para o debate na região do Maciço do Baturité, Ceará.. Fortaleza: LiberLivro, 2014. V. 1.

XAVIER, F. P.; ALVES. M. T. G. A composição social importa para os efeitos das escolas no ensino fundamental? Estudos em Avaliação Educacional, São Paulo, v. 26, n. 61, p. 216-43, jan./abr. 2015. doi:10.18222/eae266102933

WEBER, M. Résultat: confucionisme et puritanisme. In:

Confucianisme et taoisme. Paris: Gallimard, 2000. (Bibliothèques des sciences humaines). p. 310-11. 
WEINSTEIN, J.; MUNÕZ, G. Cuando los atribuciones no bastan: liderazgo directivo y gestión pública o privada de escuelas en Chile. In . Qué sabemos sobre los diretores de escuelas em Chile? Santiago: Fundación Chile, Pontifícia Universidad Católica de Chile, 2012. p. 55-79.

\section{Informações dos autores}

André Haguette: Doutorado em Sociologia. Professor titular da Universidade Federal do Ceará - UFC. Contato: haguetteandre@gmail.com

Márcio Kleber Morais Pessoa: Mestre em Sociologia pela Universidade Federal do Ceará - UFC. Professor efetivo da Rede Estadual de Educação Básica do Estado do Ceará. Contato: mkpceara@hotmail.com

Eloísa Maia Vidal: Doutorado em Educação pela Universidade Federal do Ceará-UFC. Professora adjunta da Universidade Estadual do Ceará - UECE. Contato: eloisamvidal@yahoo.com.br 